\title{
Japanese Informatization Teaching Model Based on MOOC
}

\author{
https://doi.org/10.3991/ijet.v13i07.8800 \\ Guozheng Fang \\ Mudanjiang Normal University, Heilongjiang, China \\ guozhengfang2010@163.com
}

\begin{abstract}
In view of the lack of evaluation of learning effectiveness in Japanese MOOC teaching, the students' primary data on the effectiveness of Japanese learning on the MOOC platform were collected. Combined with the questionnaire and the learner's learning experience, a Japanese language informatization teaching effectiveness model based on MOOC was constructed. The effectiveness of learning Japanese in MOOC learning mode was demonstrated. The results showed that the MOOC-based Japanese informatization teaching effectiveness model could accurately reflect the learner's learning effectiveness of online Japanese learning. It also has certain reference value for the demonstration of the effectiveness of MOOC in other areas of teaching and learning.
\end{abstract}

Keywords-MOOC, Japanese language learning, informatization teaching, effectiveness model

\section{Introduction}

The development of mobile learning and the open education movement have greatly promoted the development of online learning. The current hottest form of online learning is the MOOC (Massive Open Online Course). The MOOC was first proposed in 2008 and reached a climax in 2012. The New York Times attributed 2012 to the first year of MOOC. John Hennessy believes that this innovative approach to online education not only has an impact on online education and higher education, but also has a huge impact on the entire Internet industry. It is called "a digital tsunami." During 2012, the MOOC storm began to swiftly start in the United States. Three giant Udacity, Coursera, EDX platform gradually rises, and forms a situation of tripartite confrontation. After that, other countries in the world have also joined in, such as China's MOOC platform founded by Tsinghua University. As of October 2016, the locations of the several platforms presented on the MOOC MAP are located. It can be seen that the storm of MOOC has already engulfed many developed and developing countries. 


\section{State of the art}

Research on MOOCs at home and abroad mostly focuses on the teaching mode, business model, MOOC form analysis, and the future development of MOOCs. There is less research on user perspectives. Users of the MOOC platform were studied. The relevant literature at home and abroad was summarized. User research focuses on two aspects: user experience and user behavior.

Currently, research on the user experience of the MOOC platform focuses on usability. Domestic and foreign scholars are from system-centered to user-centered. It presents a gradual improvement and in-depth trend. From the point of view of the learning platform or system, Feng T [1] divided usability according to the system interface, function, and structural design. In 2016, Lijun Q and Zuoyong N [2] evaluated the COPD learning resource platform from the four dimensions of interaction and navigation, content system, interface design, and information design. Zhuo $\mathrm{C}$ and Dong X [3] pointed out that user-centered refers to the division of users' use as the center and divides them into dimensions such as efficiency, effectiveness, and satisfaction. This theoretical structure is clearer and meets the principle of user experience from a psychological perspective, which can reflect the user's experience well. In 2014, Yunus MM et al. [4] considered that the availability evaluation of E-learning should start from the dimensions of validity, efficiency and satisfaction. In 2014, Stellefson $\mathrm{M}$ et al. [5] used multiple methods from the dimensions of usability, efficiency, memory, and satisfaction to investigate.

In terms of user behavior, Asarbakhsh $\mathrm{M}$ and Sandars $\mathrm{J}$ [6] mainly conducted research on two aspects: user completion rate and participation, and continuous use behavior. In 2011, Granic A and Cukusic M [7] analyzed the impact factors of user participation in MOOC learning through the analysis of 6.9 million MOOC videos, and analyzed the user behaviors of various online courses. The results show that video length, teacher's speaking speed, video type, production style and other factors have an important influence on students' choice of MOOC. The more popular conclusions of short video and suggestions for the production of a series of video lessons were proposed. In 2015, Godwin-Jones R [8] studied the impact of curriculum characteristics (including course length, school rankings, registration numbers, etc.) on student learning outcomes.

In summary, scholars' research on MOOC platform users mainly focuses on user experience and user behavior. However, there is little research on the teaching effectiveness of the MOOC platform for users, and there is a lack of theoretical and empirical research.

\section{$3 \quad$ Methodology}

\subsection{Evaluation of key factors}

Questionnaire surveys were conducted to evaluate the effectiveness of MOOC Japanese language learning. In order to ensure the validity of the questionnaire design, 
from the perspective of online course design, the research results of related factors that affect online learning are sorted out. Scholars believe that curriculum flexibility, number of courses, student satisfaction with the media, curriculum satisfaction, curriculum communication, interaction flexibility, system operation, curriculum content, organizational form of learning activities, design of teaching, design of interface, and technology are related to the effectiveness of learning. From the factors of scholars' research, combined with the perspective of curriculum design, the factors affecting the effectiveness of online learning are categorized into three aspects: curriculum content, curriculum organization (teaching design), and curriculum evaluation.

Because the Japanese language learning activities in this article include all activities in the learning process, the curriculum assessment is integrated into the curriculum organization. The form and subject of the course assessment are directly related to the effectiveness of the course. Therefore, from the point of view of the Japanese curriculum design, the key factors of MOOC learning effectiveness are summarized as shown in Table 1.

Table 1. Key factors affecting the effectiveness of MOOC learning

\begin{tabular}{|c|c|}
\hline First-level factors & Secondary factors \\
\hline \multirow{4}{*}{ Course content } & Correctness \\
\cline { 2 - 2 } & Scientific \\
\cline { 2 - 2 } & Usefulness \\
\cline { 2 - 2 } Course organization & Extensibility \\
\hline \multirow{4}{*}{ Course flexibility } \\
\cline { 2 - 2 } & Presentation of learning activities \\
\cline { 2 - 2 } & Organization of learning activities \\
\cline { 2 - 2 } & Effectiveness of learning activities \\
\cline { 2 - 2 } & Assessment method \\
\cline { 2 - 2 } & Assessment subject \\
\hline
\end{tabular}

\subsection{Design and collection of questionnaire}

According to the key factors listed in Table 1, a questionnaire was designed, as shown in Table 2.

This questionnaire is divided into three parts. It includes the background of the learner, the teaching content of the sample curriculum, and the teaching activities of the Japanese curriculum. There are 11 objective questions. Among them, questions 13 belong to the background of the survey learners. Questions 4-5 are to investigate the usefulness and expandability of the teaching content of the Japanese language course. Questions 6-9 are used to investigate the rationality and presentation of teaching activities. Questions 10-11 deal with the evaluation of teaching activities and the effectiveness of teaching activities. 
Table 2. Questionnaire

\begin{tabular}{|c|c|}
\hline Question of investigation & Answer choice \\
\hline What's your occupation? & A. Student; B. Workers \\
\hline What is your major? & A. Engineering; B. Science; C. Liberal Arts \\
\hline What do you know about MOOC? & $\begin{array}{l}\text { A. Took a Japanese course, but did not finish it; B. } \\
\text { Took Japanese courses and finished teaching videos; } \\
\text { C. Completed the Japanese course and passed the } \\
\text { course examination. }\end{array}$ \\
\hline $\begin{array}{l}\text { Do you think that the teaching content of the Japane- } \\
\text { se language course has an effect on your work or } \\
\text { Japanese language learning? }\end{array}$ & A. A bit of a role; B. Very useful; C. No effect at all \\
\hline $\begin{array}{l}\text { Do you think that the teaching content of the Japane- } \\
\text { se course is interlinked? }\end{array}$ & A. Yes; B. No; C. Not clear \\
\hline $\begin{array}{l}\text { What is the average time you spend learning a } \\
\text { Japanese language course each day? }\end{array}$ & $\begin{array}{l}\text { A. Within } 15 \text { minutes; B. } 15-30 \text { minutes; C. } 30-60 \\
\text { minutes; D. } 1 \text { hour or more }\end{array}$ \\
\hline $\begin{array}{l}\text { Do you think the time spent on learning a Japanese } \\
\text { course is reasonable? }\end{array}$ & $\begin{array}{l}\text { A. Totally unreasonable; B. Not reasonable; C. } \\
\text { Relatively reasonable; D. Very reasonable }\end{array}$ \\
\hline $\begin{array}{l}\text { Which of the following are your learning behaviors } \\
\text { for participating in Japanese language courses? } \\
\text { (Multi-choice questions) }\end{array}$ & $\begin{array}{l}\text { A. Watch the instructional video; B. Participate in } \\
\text { the discussion area; C. Browse only the discussion } \\
\text { area and do not participate; D. Read the text materi- } \\
\text { al; E. Test }\end{array}$ \\
\hline $\begin{array}{l}\text { What do you think is the biggest difference between } \\
\text { this Japanese course and other courses? }\end{array}$ & $\begin{array}{l}\text { A. Diverse learning activities; B. Short videos; C. } \\
\text { Clear learning objectives; D. Same as others }\end{array}$ \\
\hline What is your favorite evaluation method? & $\begin{array}{l}\text { A. Test evaluation; B. Job evaluation; C. Learner } \\
\text { evaluation; D. Instructor rating }\end{array}$ \\
\hline $\begin{array}{l}\text { Do you think that the learning objectives that were } \\
\text { originally proposed in the Japanese language course } \\
\text { have been reached after the completion of the study? }\end{array}$ & A. Yes; B. No \\
\hline
\end{tabular}

\subsection{Data analysis and statistics}

The premise of scientific, reasonable and authentic questionnaire survey results is that there are enough sample sizes and as close as possible to the target population. In order to make the questionnaire data real and reliable, questionnaires were issued in multiple ways. The investigation time of the questionnaire lasted from February 17, 2017 to March 17, 2017, and lasted for approximately one month. A total of 250 questionnaires were distributed during the questionnaire collection period. Thirty-two invalid questionnaires that did not answer complete and apparently free responses were discarded. Finally, 218 valid questionnaires were obtained, with an effective rate of $87.2 \%$.

In terms of demographic characteristics, there is no significant correlation between gender and age and the effectiveness of MOOC learning in Japanese. Therefore, gender and age are not used as control variables. Reliability refers to the reliability of the questionnaire sample data. It can quantify the credibility of the questionnaire data and test the consistency and stability of the results. According to American statisticians, the Cronbach Alpha coefficient is between 0.00 and 1.00 . If it is less than 0.5 , the 
reliability is low. If the coefficient is between 0.5 and 0.7 , reliability is acceptable. If the coefficient is greater than 0.7 , the reliability is good.

The validity analysis is an analysis of the validity of the questionnaire. Factor analysis first needs to perform KMO test and Bartlett's sphere test on 13 observation variables to judge whether the questionnaire can be used for factor analysis. The KMO statistic is between $0-1$. If the KMO statistic is close to 1 , the scale is more suitable for factor analysis.

$\mathrm{R}$ language is used for reliability and validity processing. The data processing results showed that the overall Cronbach Alpha coefficient of the scale was 0.96. As a whole, the evaluation index system of Japanese learning effectiveness based on the MOOC platform has a high level of reliability. The KMO value and Bartlett's spherical test results are shown in Table 6. According to the test statistics, the KMO of the scale is 0.93 , which is very suitable for factor analysis. Bartlett's spherical test statistic observations were 1947.75 . Correspondingly, if the probability $\mathrm{P}$ is close to 0 , the hypothesis is rejected. It believes that the variables are not independent. Therefore, it can do factor analysis.

Table 3. KMO value and Bartlett's spherical test result

\begin{tabular}{|c|c|c|c|}
\hline \multirow{2}{*}{ KMO sample measure } & \multicolumn{3}{|c|}{ Bartlett's spherical inspection } \\
\cline { 2 - 4 } & Chi-square value & Significant level & Degree of freedom \\
\hline 0.93 & 1946.756 & 0 & 326 \\
\hline
\end{tabular}

\subsection{Subjective weight gain of model}

The ultimate goal of establishing an evaluation model based on the MOOC platform's Japanese language learning effectiveness is to obtain the importance of each index. As the model is still not quantified, it cannot be directly used for the evaluation of the MOOC platform. Therefore, it is indispensable to rank the indicators of the index system. The main method of importance ranking is empowerment, which uses a combination of subjective weighting of analytic hierarchy process and objective weighting of factor analysis. It is the most scientific and objective to ensure the weight of the model.

The methods for determining subjective weights are mainly expert rating and analytic hierarchy process. The expert rating method completely depends on the expert's personal knowledge level and rich experience. Subjectivity is too strong, so this method is abandoned. The main ideas of the AHP are consistent with the research ideas. The research idea of the analytic hierarchy process is to first analyze the different influencing factors on practical problems. Then, different influencing factors are assigned to different levels, a judgment matrix is constructed, and weights are calculated. From the perspective of MOOCs learning key factors of effectiveness, three levels have been established. Then, the matrix is constructed by AHP to calculate the weights. The results are shown in Table 4. 
Table 4. KMO value and Bartlett's spherical test result

\begin{tabular}{|c|c|c|}
\hline Target layer & First-level indicators & Secondary indicators \\
\hline \multirow{10}{*}{$\begin{array}{l}\text { Japanese Informatization Teaching } \\
\text { Achievement Model Index Based } \\
\text { on MOOC(A) }\end{array}$} & \multirow{4}{*}{ Course content $(\mathrm{C} 1)$} & Correctness (P1) \\
\hline & & Scientific (P2) \\
\hline & & Usefulness (P3) \\
\hline & & Extensibility (P4) \\
\hline & \multirow{6}{*}{ Course organization $(\mathrm{C} 2)$} & Course flexibility (P5) \\
\hline & & $\begin{array}{c}\text { Presentation of learning activities } \\
\text { (P6) }\end{array}$ \\
\hline & & $\begin{array}{l}\text { Organization of learning activities } \\
\text { (P7) }\end{array}$ \\
\hline & & $\begin{array}{c}\text { Effectiveness of learning activities } \\
\text { (P8) }\end{array}$ \\
\hline & & Evaluation method (P9) \\
\hline & & Assessor (P10) \\
\hline
\end{tabular}

Because experts choose to follow the odd-numbered principle, five experts are selected, and there are two conditions for their selection. One is the university's serving teachers; the other is the teachers' publicly published articles on topics such as "MOOC", "Online Learning", "Internet Education". Analytic software Yaahp is used to analyze expert data.

After collecting expert scoring results, formula (1) is used to make the following statistics. In the formula, $b_{j i}$ denotes the magnitude of the degree $j$ of the index $i . n_{i j}$ denotes the number of experts who are rated as important to the ith index.

$$
b_{i j}=\frac{1}{p} \sum_{j=1}^{5} b_{j}^{i} n_{i j}
$$

First, the weights of the indicators in the target layer are calculated in the total system. Then, the weight of the secondary index $\mathrm{P}$ at the primary index layer $\mathrm{C}$ is calculated. The above calculation results are summed up, and the weight of the evaluation model of Japanese informatization teaching effectiveness based on MOOC is finally determined.

\section{$4 \quad$ Result analysis and discussion}

\subsection{Analysis of survey results}

Through the analysis of the data of the sample, it was found that most of the respondents to the questionnaire were students. The proportion is $94.03 \%$, as shown in Figure 1. Among them, liberal arts students accounted for the largest proportion. The proportion is $45.86 \%$. Engineering and science were $31.71 \%$ and $22.43 \%$, respectively, as shown in Figure 2. Among the respondents, most of the users completed the Japanese course and passed the course examination. The proportion is $72.47 \%$, as 
shown in Table 5. They can help this survey to more truly understand the effectiveness of Japanese language learning based on the MOOC platform.

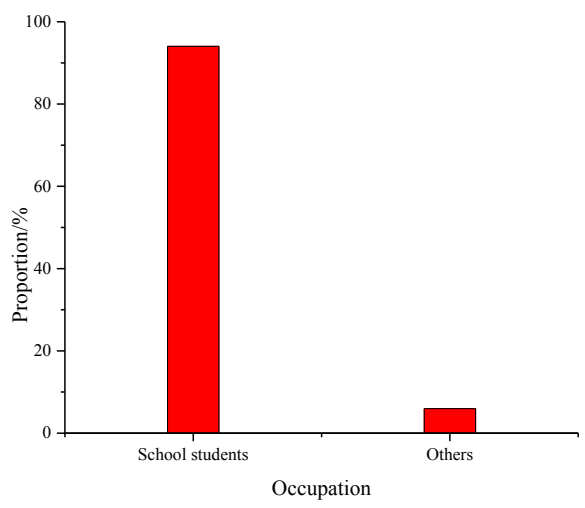

Fig. 1. Occupations of MOOC Japanese language learning user

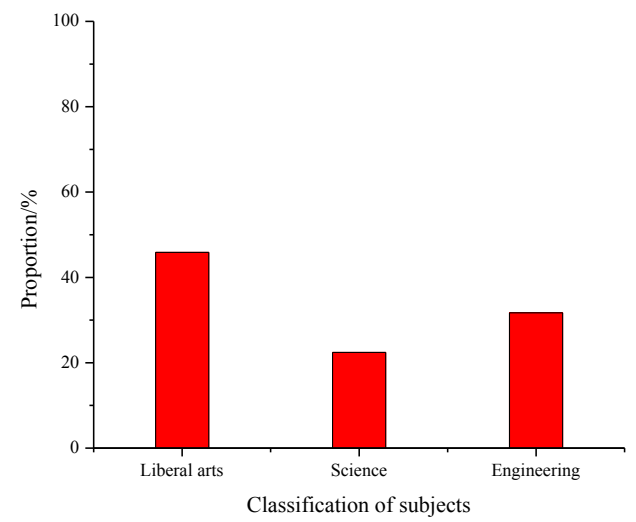

Fig. 2. Constitution of MOOC Japanese language learning users' disciplines

Table 5. MOOC learning courses for users in Japanese

\begin{tabular}{|l|l|}
\hline \multicolumn{1}{|c|}{ The situation of learning courses } & \multicolumn{1}{|c|}{ Proportion } \\
\hline Took a Japanese course, but did not finish it & $11.02 \%$ \\
\hline Took Japanese courses and finished teaching videos & $16.51 \%$ \\
\hline $\begin{array}{l}\text { Completed the Japanese course and passed the } \\
\text { course examination }\end{array}$ & $72.47 \%$ \\
\hline
\end{tabular}

The usefulness of the sample curriculum is shown in Figure 3. $70 \%$ of the choices are very useful, and most of them are learners from universities. $30 \%$ of the choices have a little effect, and most of the people are from corporate learners. No one chooses no effect. Therefore, the content of the course has a certain role for both corporate learners and college learners. It can help to learn or work in a certain sense. 


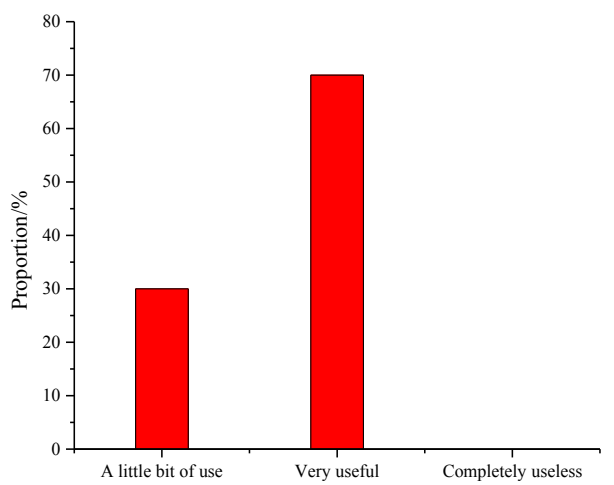

Fig. 3. Survey of the usefulness of the course content

According to the survey results (as shown in Figure 4), $72.5 \%$ think that the course content is not interlocking. In addition to learning activities that must be learned, learners can choose their own learning steps. It gives learners great autonomy. However, $17.5 \%$ still believe that the course content needs activity learning. $10 \%$ of the learning steps of the course content are not clear. Therefore, the design of learning activities also needs to reduce the coupling between each learning activity.

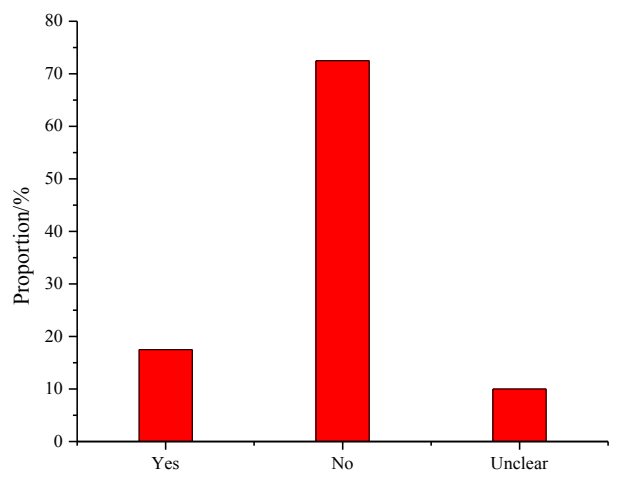

Fig. 4. Coupling between learning activities

As shown in Figures 5 and 6, learners spend an average of 15-30 minutes and 3060 minutes each day. Most corporate learners spend 15-30 minutes. College learners are relatively rich because of the time, and most of them are 30-60 minutes. Each learning activity requires no more than 30 minutes. Therefore, learners basically believe that the time for learning a learning activity is more consistent with their own learning time. Over $85 \%$ of learners believe that the time required for learning activities is reasonable. 


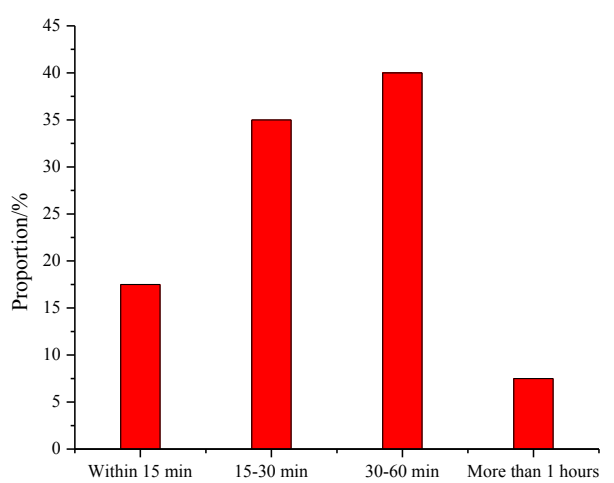

Fig. 5. Learner's average daily learning time

Table 6. The rationality of the time of learning activities

\begin{tabular}{|l|c|}
\hline \multicolumn{1}{|c|}{ Rationality } & Proportion \\
\hline Totally unreasonable & $0 \%$ \\
\hline Not reasonable & $17.5 \%$ \\
\hline Relatively reasonable & $52.5 \%$ \\
\hline Very reasonable & $32.5 \%$ \\
\hline
\end{tabular}

As shown in Table 7, in the learning process, the most activity for learners is to watch teaching videos, followed by text reading. These two learning activities also occupy a dominant position in the learning process. Relatively speaking, testing and discussion areas are not very involved. There are two reasons for the analysis. One is that testing is a separate activity. Due to platform limitations, learners cannot be tested directly under the course page. This tedious operation will lead to a group of learners who are reluctant to participate in the test. Second, the location of the discussion area is not significant enough. The place for discussion is below the micro video. Some learners think that the learning activity has been completed after watching the micro video.

According to the survey results (as shown in Table 8), the MOOC Japanese language course is compared with other courses. The biggest difference is the diversity of learning activities. Compared with other video-only questions, there is more novelty. Videos are short and learners can learn effectively.

Table 7. The setting of learning activities

\begin{tabular}{|l|c|}
\hline \multicolumn{1}{|c|}{ Learning activities } & Proportion \\
\hline Watch the instructional video & $97.5 \%$ \\
\hline Participate in the discussion area & $60 \%$ \\
\hline Browse only the discussion area and do not participate & $32.5 \%$ \\
\hline Read the text material & $87.5 \%$ \\
\hline Test & $67.5 \%$ \\
\hline
\end{tabular}


Paper-Japanese Informatization Teaching Model Based on MOOC

Table 8. The features of MOOC Japanese course

\begin{tabular}{|l|c|}
\hline \multicolumn{1}{|c|}{ Curriculum features } & Proportion \\
\hline Diverse learning activities & $45 \%$ \\
\hline Shorter video & $32.5 \%$ \\
\hline Clear learning goals & $20 \%$ \\
\hline Same as other & $2.5 \%$ \\
\hline
\end{tabular}

The evaluation methods of the course include three kinds of evaluation methods: test evaluation, job evaluation and peer evaluation. For learners, the favorite evaluation method is test evaluation, as shown in Figure 6. It can intuitively detect students' learning effect. Some learners also express peer reviews, because online learning is uncertain. Sometimes there will be no peer evaluation. Therefore, the course assessment method should take into account some relatively simple test questions related to the teaching content. It can both give learners feedback and encourage learners to continue learning.

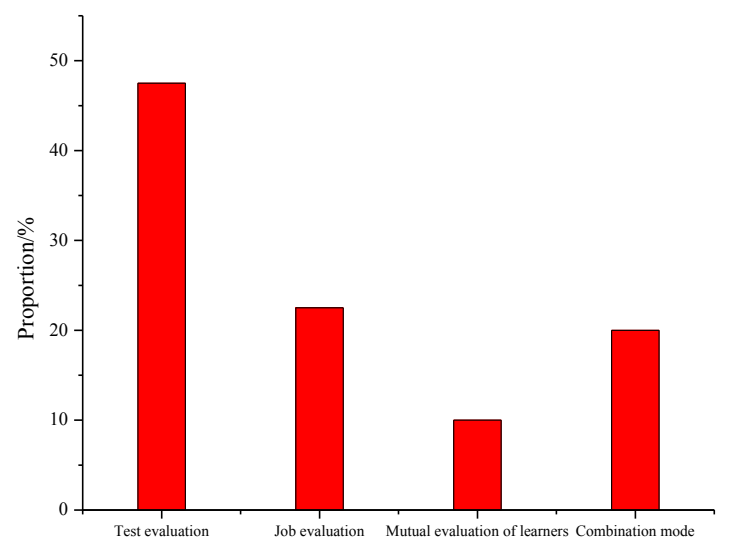

Fig. 6. The evaluation method of Japanese course

Samples of the curriculum indicate the final assessment assignments when learning objectives. In the setting of learning activities, the design MOOC is set as a mustlearning link. As a result, learners achieving learning goals reached $72.5 \%$, as shown in Figure 7. Learning activities can, to a certain extent, promote the achievement of learning goals.

Through a questionnaire survey of the effectiveness of the MOOC Japanese language curriculum, most learners basically achieved the learning objectives set by the curriculum. Learners are more satisfied with MOOC-based Japanese language courses and learners have higher completion rates. Most learners insisted on completing the course and conducted the final test. Therefore, it also indirectly proves that MOOCbased Japanese language teaching is favored by learners to a certain extent. 


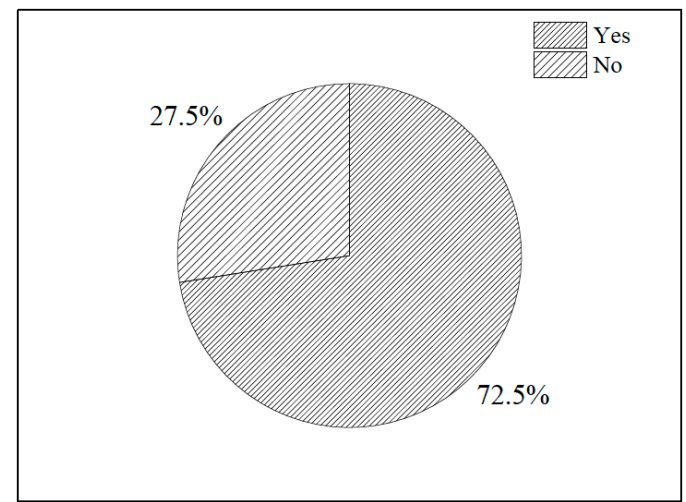

Fig. 7. The realization of learning goal

\subsection{Subjective weight of effectiveness evaluation model}

According to formula (1), the weight of each level is calculated separately. Finally, the results are summarized. The weights of the evaluation model for Japanese informatization teaching based on MOOC were determined, as shown in Table 8.

Table 9. The weights of the Japanese MOOC-based effectiveness assessment model determined by the analytic hierarchy process

\begin{tabular}{|c|c|c|c|c|}
\hline Target layer & $\begin{array}{c}\text { First-level indica- } \\
\text { tors }\end{array}$ & Priority weight & $\begin{array}{c}\text { Secondary indica- } \\
\text { tors }\end{array}$ & Priority weight \\
\hline \multirow{10}{*}{$\begin{array}{l}\text { Japanese Informa- } \\
\text { tization Teaching } \\
\text { Achievement Model } \\
\text { Index Based on } \\
\text { MOOC(A) }\end{array}$} & \multirow{4}{*}{ Course content $(\mathrm{C} 1)$} & \multirow{4}{*}{0.3805} & Correctness (P1) & 0.0564 \\
\hline & & & Scientific (P2) & 0.0567 \\
\hline & & & Usefulness (P3) & 0.0517 \\
\hline & & & Extensibility (P4) & 0.0601 \\
\hline & \multirow{6}{*}{$\begin{array}{l}\text { Course organization } \\
\text { (C2) }\end{array}$} & \multirow{6}{*}{0.6195} & $\begin{array}{c}\text { Course flexibility } \\
\text { (P5) }\end{array}$ & 0.2022 \\
\hline & & & $\begin{array}{l}\text { Presentation of } \\
\text { learning activities } \\
\text { (P6) }\end{array}$ & 0.2082 \\
\hline & & & $\begin{array}{l}\text { Organization of } \\
\text { learning activities } \\
\text { (P7) }\end{array}$ & 0.2242 \\
\hline & & & $\begin{array}{l}\text { Effectiveness of } \\
\text { learning activities } \\
\text { (P8) }\end{array}$ & 0.0508 \\
\hline & & & $\begin{array}{l}\text { Evaluation method } \\
\qquad \text { (P9) }\end{array}$ & 0.0505 \\
\hline & & & Assessor (P10) & 0.0392 \\
\hline
\end{tabular}

From Table 8, it can be seen that in the ten index systems, the rights of the course organization are more important than the course content. The flexibility of courses, the presentation of learning activities, and the organization of learning activities have 
a higher weight in all secondary indicators. This means that these three aspects have the greatest impact on the effectiveness of MOOC Japanese teaching. In order to improve the effectiveness of the MOOC platform for Japanese language teaching, improvements can be made from these three aspects.

\section{Conclusions}

The first hand data of Japanese learners' performance on the MOOC platform are collected. Questionnaires, analytic hierarchy process, and learner's learning experience are applied. A Japanese MOIC-based information effectiveness teaching model was constructed. The key factors of effectiveness evaluation were analyzed. Based on the MOOC-based Japanese learning effectiveness model, evaluation indicators are divided into first-level indicators and second-level indicators. There are two first-level indicators and ten second-level indicators. Then, the questionnaire data was collected and analyzed. The subjective weights of the MOOC-based Japanese learning effectiveness model were derived. In the end, a Japanese language informatization teaching effectiveness model based on MOOC was established. The effectiveness of Japanese learning in the MOOC learning mode was verified. The results show that the effectiveness of the MOOC platform for Japanese language teaching can be improved from the three aspects of curriculum flexibility, the presentation of learning activities, and the organization of learning activities. The MOOC-based Japanese informatization teaching effectiveness model has certain reference value for MOOC teaching in other fields.

\section{Acknowledgement}

Fund Project: 1.Planning Project of Heilongjiang Educational Committee "Under the Background of Globalization, Cultural Construction in Translation Teaching" ( Gjc1316123) 2. Scientific Research Project of Mudanjiang Normal University " The Research on Fostering the Intercultural Communication Competence of Foreign Language Talents in Applied University" (YB 201607) 3. Doctoral Research Foundation of Mudanjiang Normal University " The Research of the Historical Crucial Reason and Historical Viewpoint of the Sino-Japanese relations in Modern Times" ( MNUB 201505)

\section{$7 \quad$ References}

[1] Feng T. (2017). Research on teaching model of MOOC-based college English flipped classroom. Boletin Tecnico/technical Bulletin, 55(20): 503-508

[2] Lijun Q, Zuoyong N. (2016). Accelerating Particle Swarm Optimization Algorithm Based on MOOC Framework for Resource Scheduling in Physical Teaching. Journal of Computational and Theoretical Nanoscience, 13(12): 9426-9430 https://doi.org/10.1166/jctn. $\underline{2016.5859}$ 
[3] Zhuo C, Dong X. (2017). An Applicable Way of Teaching Quality Evaluation Based on MOOC Platform. International Journal of Emerging Technologies in Learning, 12(3): 57 https://doi.org/10.3991/ijet.v12i03.6421

[4] Yunus MM, Hashim H, Ahmad AR, et al. (2014). MOOC as a Platform for Developing Writing Skills: Effectiveness and Challenges. Journal of Computational \& Theoretical Nanoscience, 24(1): 199-201

[5] Stellefson M, Chaney B, Chaney D. (2014). Heuristic Evaluation of Online COPD Respiratory Therapy and Education Video Resource Center. Telemedicine and E-health, 20: 972976 https://doi.org/10.1089/tmj.2014.0009

[6] Asarbakhsh M, Sandars J. (2013). E-learning: the essential usability perspective. The Clinical Teacher, 10: 47-50 https://doi.org/10.1111/j.1743-498X.2012.00627.x

[7] Granic A, Cukusic M. (2011). Usability testing and expert inspections complemented by educational evaluation: A case study of an E-learning platform. Educational Technology \& Society, 2: 107-123

[8] Godwin-Jones, R. (2015). Emerging Technologies the Evolving Roles of Language Teachers: Trained Coders, Local Researchers, Global Citizens. Language, Learning and Technology, 19(1): 10-22

\section{Author}

Guozheng Fang is with School of Oriental Languages, Mudanjiang Normal University, Heilongjiang 157013, China.

Article submitted 26 April 2018. Final acceptance 07 May 2018. Final version published as submitted by the authors. 